\title{
Credit Financing in Economic Ordering Policies for Defective Items with Order Overlapping
}

\author{
Chandra K. Jaggi, Mandeep Mittal, Jyoti Gulia, Pankaj Singh, and Ruchi Sharma
}

\begin{abstract}
In the classical inventory models, most of the time the issue of quality of the items has not been given due attention. However, in realistic environment, it can be observed that there may be some defective items in an ordered lot, because of these defective items retailer may incurs additional cost due to rejection, repair and refund etc. Thus, inspection/screening of lot becomes essential in most of the organizations. Shortages may occur due to defective items, which can be prevented by placing an order at the time when the inventory level is good enough to meet the demand during the screening process. Further, it is generally assumed that payment will be made to the supplier for the goods immediately after receiving the consignment. Whereas, in practice, supplier does offers a certain fixed period to the retailer for settling the account. During this period, supplier charges no interest, but beyond this period interest is being charged as has been agreed upon. On the other hand, retailer can earn interest on the revenue generated during this period. Keeping this scenario in mind, an attempt has been made to formulate an inventory model for imperfect quality items under the condition of permissible delay in payments. Results have been validated with the help of a numerical example. Comprehensive sensitivity analysis has also been presented.
\end{abstract}

Index Terms - Inventory, imperfect items, permissible delay, overlapping.

\section{INTRODUCTION}

In today's technology driven world, despite of efficient planning of manufacturing system and emergence of sophisticated production methods and control systems; the items produced may have some fraction of defectives. By considering this fact, researchers devoted a great amount of effort to develop EPQ/EOQ models for defective items (Porteus [1], Rosenblatt and Lee [2], Lee and Rosenblatt [3], Schwaller [4], Zhang and Gerchak [5]). In 2000, Salameh and Jaber [6] extended the traditional EPQ/EOQ model for the imperfect quality items. They also considered that the imperfect - quality items are sold at a discounted price as a single batch by the end of the screening process. CárdenasBarrón [7] corrected the optimum order size formula obtained by Salameh and Jaber [6] by adding constant parameter which was missing in their optimum order size formula. Further, Goyal and Cárdenas-Barrón [8] presented a simple approach for determining economic production

Manuscript received August 9, 2013; revised October 13, 2013.

Chandra K. Jaggi is with the Department of Operational Research, University of Delhi, India (e-mail: ckjaggi@yahoo.com).

Mandeep Mittal, Jyoti Gulia, Pankaj Singh, and Ruchi Sharma are with the Department of Computer Science Engineering, Amity School of Engineering and Technology, Bijwasan, New Delhi, India (e-mail: mittal_mandeep@yahoo.com). quantity for imperfect quality items and compare the results based on the simple approach with optimal method suggested by Salameh and Jaber [6]. Papachristos and Konstantaras [9] examined the Salameh and Jaber [6] paper closely and rectify the proposed conditions to ensure that shortages will not occur. They extended their model to the case in which withdrawing takes place at the end of the planning horizon. Further, Wee et al., [10] extended the model of Salameh and Jaber [6] for the case where shortages are back ordered in each cycle. Maddah and Jaber [11] corrected Salameh and Jaber [6] work related to the method of evaluating the expected total profit per unit time and applied renewal-reward theorem (Ross [12]). Further, Eroglu and Ozdemir [13] also extended the model of Salameh and Jaber [6] by allowing shortages to be backordered. They suggest that a fraction of good quality items in each cycle not only fulfills current demand but also fulfills backorders during screening process.

In all the above mentioned papers, it is tacitly assumed that payment will be made to the supplier for the goods immediately after receiving the consignment. However, in day-to-day dealing, it is found that the supplier allows a certain fixed period to settle the account. During this period, no interest is charged by the supplier, but beyond this period interest is charged under certain terms and conditions agreed upon, since inventories are usually financed through debt or equity. Owing to this fact, during the past few years, a lot of research work has been done on inventory models with permissible delay in payments, which has been summarized by Soni et al., [14].

Further, Chung and Huang [15] incorporated the concept of inspection of imperfect items with trade credit. Jaggi $e t$ al., [16] formulated an inventory model with imperfect quality deteriorating items with the assumption that the screening rate is more than the demand rate. This assumption helps one to meet his demand parallel to the screening process, out of the items which are of perfect quality. Recently, Maddah et al., [17] introduced the concept of order overlapping to prevent shortages. They represent an improvement in customer service level over earlier literature, when demand is assumed to be met during the screening period from the order being screened leading to potential shortages.

In this paper, an inventory model is developed for imperfect quality items under permissible delay in payments. The screening rate is assumed to be more than the demand rate. This assumption helps one to meet his demand during the screening process, out of the items which are of perfect quality. Further, to prevent shortages an order is placed during the screening process at the time when inventory level is good enough to meet demand. The proposed model 
optimizes retailer's order quantity by maximizing his expected total profit. A comprehensive sensitivity analysis has also been performed to study the impact of effective parameters.

\section{ASSUMPTIONS AND NOTATIONS}

The following assumptions are used to develop the model:

- Demand rate is known with certainty and is uniform.

- The replenishment is instantaneous.

- Shortages are not allowed

- The lead-time is negligible.

- The supplier provides a fixed credit period to settle the accounts to the retailer.

- Both screening as well as demand proceeds simultaneously, but the screening rate is assumed to be greater than demand rate.

- It is assumed that each lot contains percentage defectives of ' $p$ ' with known uniform probability function, $f(p)$.

The following notations are used in developing the model: $D$ demand rate in units per unit time

$\begin{array}{ll}y & \text { order size for each cycle } \\ K & \text { fixed Cost of placing an order } \\ c & \text { unit cost } \\ s & \text { unit selling price of perfect items } \\ v & \text { unit selling price of imperfect items } \\ h & \text { holding Cost per unit item } \\ d & \text { unit screening cost } \\ p & \text { percentage of defective items in } y \\ x & \text { screening rate in units per unit time } \\ t & \text { screening time }(=y / x y) \\ & \\ T & \text { cycle length } \\ L_{e} & \text { Interest Earned per unit time } \\ L_{p} & \text { Interest Paid per unit time } \\ M & \text { Permissible delay }\end{array}$

ETPU (y) Expected total profit per unit time cycle

\section{MATHEMATICAL MODEL}

The proposed Model assumes that a lot of $y$ units enter in the inventory system at time $t=0$ and contains ' $p$ ' percent defective items with a probability density function, $f(p)$, which can be estimated from the past data. Screening is done for the entire received lot at a rate of $\lambda$ units per unit time to separate good and defective quality items. After the end of screening process at time $t$, defective items i.e. py are sold immediately as a single batch at discounted price $v$. In order to prevent shortages during the screening process, an order is placed when the inventory level is just enough to meet the demand during the screening period. This occurs when the

$$
M \leq t \text { and } t \leq M \leq T
$$

Inventory level of the " previous" order reaches Dt, where $t=y / x$ is the duration of the screening period. Behavior of the model is depicted in Fig. 1.
The present model has been developed under the condition of permissible delay in payments; therefore, depending upon the credit period, there would be two distinct possible cases for the retailer's total profit.

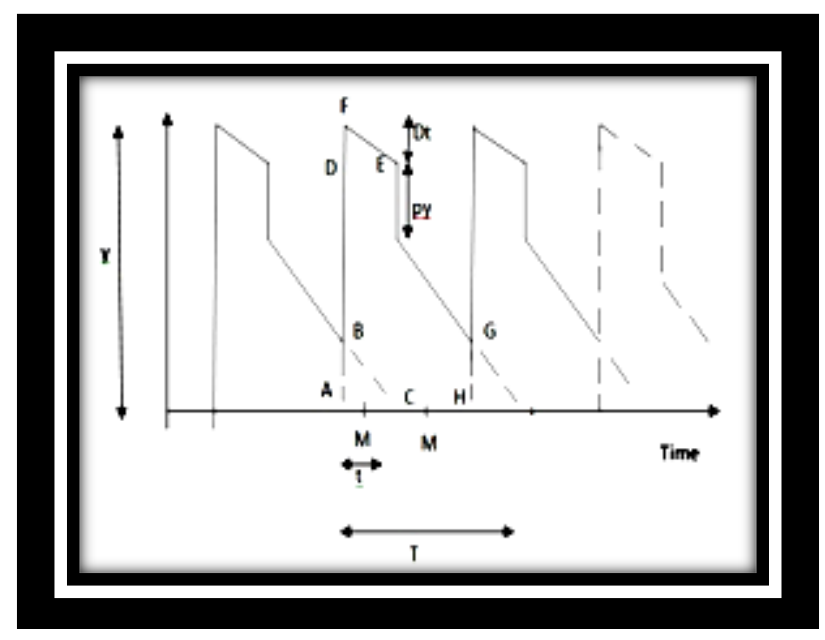

Fig. 1. Inventory system with inspection for the cases.

- Case 1: $M \leq t$

- Case 2: $t \leq M \leq T$

Since, the retailer's total profit consists of the following components:

TPU $(y)=$ Sales revenue - Ordering cost - Purchasing cost - Screening cost - Holding cost + Interest earned - Interest paid

Further, the interest earned and paid is calculated for the three different cases as follows:

- Case 1: $M \leq t$

The retailer earns interest on average sales revenue generated during time period 0 to $M$. but beyond $M$, the supplier asks for interest for the remaining stock.

The values of interest earned and interest paid by the retailer are calculated as follows:

Interest Earned $=\frac{D M^{2} p I_{e}}{2}$

The interest paid by the retailer to supplier is given as:

Interest Paid $=\frac{((1-\alpha) y-D M) I_{p} s(T-M)}{2}+v I_{p} y(t-M)$

In this case, after applying Ross [12] the expected total profit earned by the retailer is calculated using the values of interest earned and interest paid.

$$
\left.\operatorname{Etpu}(y)=\left[\begin{array}{c}
s y(1-E[p])+v y E[\mathrm{p}]-K-c y-d y \\
-h\left[\frac{(y(1-E[p]))^{2}}{2 \mathrm{D}}+\frac{y^{2}}{x}\right] \\
-\left[\frac{((1-E[p])-D M) c I p(T-M)}{2}\right] \\
+v I p E[p] y(t-M)+\left[\frac{D M^{2 l e s}}{2}\right]
\end{array}\right] / y(1-E[p]) / D\right]
$$

Our objective is to find the optimal value of order quantity by maximizing expected total profit function, which we can find out with the help of first and second 
derivatives of the expected total profit function. The necessary condition is $\frac{d E T P U(y)}{d y}=0$ and sufficient condition, $\frac{d^{2 E T P U(y)}}{d y^{2}}<0$. Optimal order quantity that maximizes $\operatorname{Etpu}(y)$ is

$$
y^{*}=\sqrt{\frac{\left[2 K D+D^{2} M^{2} I_{p} c-D^{2} M^{2} I_{e} s\right]}{h\left[(1-E[p])^{2}+\frac{2 D}{x}\right]+(1-E[p])^{2} I_{p} c+\left(\frac{2 v I_{p} \mathrm{E}[p] D}{x}\right)}}
$$

- Case 2: $t \leq M \leq T$

Similarly as case, the value of interest earned and interest paid are,

$$
\begin{gathered}
\text { Interest Earned }=\frac{D M^{2} I_{e} p}{2}+v p I_{e} y \frac{D M^{2} \in S}{2}+p y t v l \\
\text { Interest Paid } l_{p}=\frac{((1-\alpha) y-D M) I_{p} s(T-M)}{2}+v I_{p} y(t-M) \\
\left.\left[\begin{array}{c}
\text { Etpu }(y)=s y(1-E[p])+v y E[p]-K-c y-d y \\
-h\left[\frac{(y(1-E[p]))^{2}}{2 D}+\frac{y^{2}}{x}\right] \\
-\frac{((1-E[p])-D M) c I_{p}(T-M)}{2} \\
+\frac{D M^{2} I_{e} s}{2}+E[p] y t v I_{e}
\end{array}\right] /\left(\frac{(1-E[p]) y}{D}\right)\right] \\
\left.\left(D M^{\uparrow} 2 l e s\right) / 2+(p y t v l e) /(1-p) y / D\right)
\end{gathered}
$$

Similarly as case, optimal value of $y$ for case will be,

$$
y^{*}=\sqrt{(}\left(\frac{\left[2 K D+D^{2} M^{2} I_{p} c-D^{2} M^{2} I_{e} s\right]}{h\left[(1-E[p])^{2}+\frac{2 D}{x}\right]+(1-E[p])^{2} I_{p} c}\right)
$$

\section{AN ILLUSTRATIVE EXAMPLE}

An example is devised to illustrate the effect of permissible delay in payments on the retailer's ordering policy for the developed model using the following data.

$D=50000$ units/year, $K=\$ 100 /$ cycle, $h=\$ 4 /$ unit $/$ year, $\lambda=$ 60000unit/year, $c=\$ 25 /$ unit, $s=\$ 50 /$ unit, $v=\$ 20 /$ unit, $I e=0.12$, $I p=0.15$ and $d=\$ 0.5 /$ unit, percentage defective random variable $\mathrm{p}$ with its pdf,

$$
f(p)=\left\{\begin{array}{ll}
10, & 0 \leq \alpha \leq 0.1, \\
0, & \text { otherwise }
\end{array} E[p]=0.05\right.
$$

$M=4$ days.

Results are obtained using the solver as: $y=1002$ units, Substituting the optimal value of $y$ in the expected total profit equation,

$T=0.0190$ year, $t=0.0057$ year and $\operatorname{ETPU}(y)=\$ 1202826$

Now, if supplier offers no trade credit, i.e. $M=0$, we get: $y=1302$ units, Substituting the optimal value of $y$ in the expected total profit equation,

$T=0.0247$ year, $t=0.0074$ year and $\operatorname{ETPU}(y)=\$ 1202445$.
Findings clearly suggest that the presence of trade credit has got positive effect on retailer ordering policy. The retailer should order more frequently to avail the benefit of permissible delay in payments which results in higher expected total profit.

\section{SENSITIVITY ANALYSIS}

Sensitivity analysis has been performed to study the impact of permissible delay $(M)$, expected number of imperfect quality items $(E[\alpha])$ on the lot size $(y)$ and the retailer's expected total profit. Some results have been shown in Fig. 2 and Fig. 3.

$\mathbf{E}[\mathrm{p}]$ vs $\mathbf{y}$

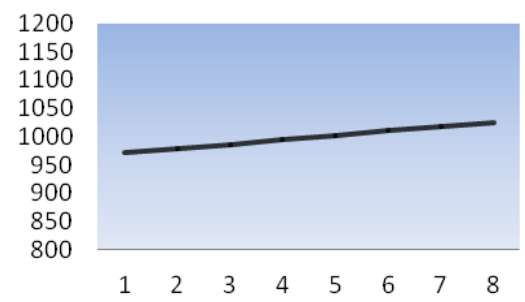

Fig. 2. Expected no. of imperfect quality items and optimal order quantity

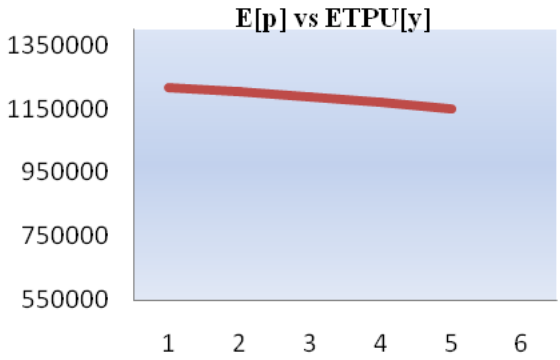

Fig. 3. Expected no. of imperfect quality items and expected total profit.

\section{CONCLUSION}

This paper presents a profit maximizing inventory model for an order when supplier offers a certain fixed credit period (Permissible delay period) that determines the optimal order quantity and maximized expected total profit. Following are some observations from the results by numerical example, Fig. 2 and Fig. 3.

- When the permissible delay is increased, then retailer should order more frequently and can earn good interest. This will produce more profit on the retailer's side.

- It is evident from Fig. 2, when the defective item increases, in such a situation, the retailer needs to order more and he should improve the quality of supply.

- Fig. 3 shows when the defective items increases then the retailer expected total profit decreases and the retailer needs to monitor the supply source.

In this paper, we have developed an inventory model for imperfect quality items under the condition of permissible delay in payments. Results have been validated with the help of a numerical example. Comprehensive sensitivity analysis has also been presented. This inventory model can 
be used to take the corrective measures in order to optimize the order overlapping in inventories to avoid shortages and to maximize the expected profit.

\section{FUTURE SCOPE}

Further, the proposed model can be extended for more realistic situations such as deteriorating items, stock dependent and stochastic demand with partial- trade credit, inflation etc.

\section{ACKNOWLEDGMENT}

We would like to acknowledge everybody who, though remain unmentioned, yet have been connected with our project directly or indirectly and entire staff of ASET for all their understanding and cooperation.

\section{REFERENCES}

[1] E. L. Porteus, "Optimal lot sizing, process quality improvement and setup cost reduction," Oper. Res., vol. 34, pp. 137-144, 1986.

[2] M. Rosenblatt and H. Lee, "Economic production cycles with imperfect production processes," IIE Trans., vol. 18, pp. 48-55, 1986.

[3] H. L. Lee and M. J. Rosenblatt, "Simultaneous determination of production cycles and inspection schedules in a production system," Manag. Sci., vol. 33, pp. 1125-1137, 1987.

[4] R. L. Schwaller, "EOQ under inspection costs," Prod. Inv. Man., vol. 29, pp. 22-24, 1988.

[5] X. Zhang and Y. Gerchak, "Joint lot sizing and inspection policy in an EOQ model with random yield," IIE Trans, vol. 22, pp. 41-47, 1990.

[6] M. K. Salameh and M. Y. Jaber, "Economic production quantity model for items with imperfect quality," Int. J. Prod. Econ., vol. 64 pp. 59-64, 2000.

[7] L. E. C. Barrón, "Observation on: Economic production quantity model for items with imperfect quality," I. J. Prod. Econ., vol. 67, pp. $201,2000$.

[8] S. K. Goyal and L. E. C. Barrón, "Note on: Economic production quantity model for items with imperfect quality - a practical approach," I. J. Prod. Econ., vol. 77, pp. 85-87, 2002.

[9] S. Papachristos and I. Konstantaras, "Economic ordering quantity models for items with imperfect quality," I. J. Prod. Econ., vol. 100, pp. 148-154, 2006.

[10] H. M. Wee, J. Yu, and M. C. Chen, "Optimal inventory model for items with imperfect quality and shortage backordering," OMEGA, vol. 35, pp. 7-11, 2007.

[11] B. Maddah, and M. Y. Jaber, "Economic order quantity for items with imperfect quality: revisited," I. J. Prod. Econ., vol. 112, pp. 808-815, 2008.

[12] S. M. Ross, Stochastic Processes, Second ed., Wiley, New York, 1996.

[13] A. Eroglu and G. Ozdemir, "An economic order quantity model with defective items and shortages," I. J. Prod. Econ., vol. 106, pp. 544 549, 2007.

[14] H. Soni, N. H. Shah, and C. K. Jaggi, "Inventory models and trade credit," J. Con. Cyb., vol. 39, pp. 867-882, 2010.

[15] K. J. Chung and Y. F. Huang, "Retailer's optimal cycle times in the EOQ model with imperfect quality and permissible credit period," $J$. Qual. Quan., vol. 40, pp. 59-77, 2006.

[16] C. K. Jaggi, S. K. Goel, and M. Mittal, "Economic order quantity model for deteriorating items with imperfect quality and permissible delay on payment," I. J. Ind. Eng. Comp., vol. 2, pp. 237-248, 2010.

[17] B. Maddah, M. K. Salameh, and L. M. Haidar, "Order overlapping: A practical approach for preventing shortages during screening," Comp. and Indus. Eng., vol. 58, pp. 691-695, 2010.

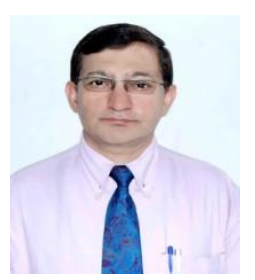

Chandra K. Jaggi was at the Department of Operational Research, University of Delhi, Delhi, India. His research interest lies in the field of supply chain and inventory management. He has published more than 88 papers in various international/national journals including Int. J. Production Economics, European Journal of Operational Research, Applied Mathematics and Computation Journal of Operational Research Society, Int. Journal of Systems Science, Int. J. Operational Research, Int. J. Services Operations and Informatics, Int. Journal of Strategic Decision Sciences, TOP, etc. He has guided 7 Ph.D. and 17 M. Phil. in operations research. He is the editor-in-chief of Intl Journal of Inventory Control and Management and associate editor of Intl J. of System Assurance Engineering and Management, Springer, co-editor / reviewer-in-charge of The GSTF JMSOR and on the Editorial Board of the Int. J. Services Operations and Informatics. American Journal Operational Research and Int. Journal of Enterprise Computing and Business Systems. He was awarded Shiksha Rattan Puraskar in 2007 and in 2009 was awarded Certificate for Significant Contributions in Operation Management by the Society of Reliability Engineering, Quality and Operations Management, New Delhi. Fellow Member, International Science Congress Association, since 2012. He has traveled extensively in India and abroad and delivered key note, plenary and invited talks.

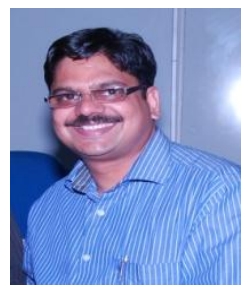

Mandeep Mittal is an assistant professor in the Department of Computer Science and Dean (Student's Activities) at Amity School of Engineering and Technology, New Delhi, India. He has completed his Ph.D on inventory control and management from University of Delhi and M.Sc. on applied mathematics from IIT Roorkee, India. He has published a number of research papers in International Journals including Applied Mathematics and Computation, Int. Journal of Systems and Science, Int. Journal of Inventory Control and Management, Int. Journal of Applied Industrial Engineering, Int. Journal of Industrial Engineering Computations, Int. Journal of Strategic Decision Sciences, Int. Journal of Services Operations and Informatics and Int. Journal Revista Invetigacion Operacional. $\mathrm{He}$ is a member of editorial board, Int. Journals Revista Invetigacion Operacional and Int. Journal of Control and Systems Engineering".

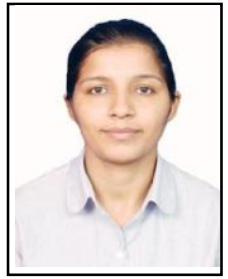

Jyoti Gulia has completed her bachelor degree in computer science \& engineering from Amity Schoo of Engineering and Technology, New Delhi in July 2013 from IP University, Delhi. She has presented a paper on Credit financing in economic order policies for defective items with order overlapping in International conference on reliability, infocom, technologies and optimization in January 2013 at Amity University Noida, Uttar Pradesh.

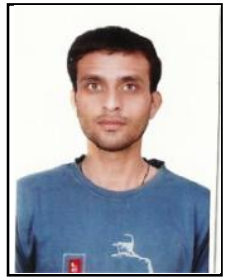

Pankaj Singh has completed his bachelor degree in computer science \& engineering from Amity School of Engineering and Technology, New Delhi in July 2013 from IP University, Delhi. He has presented a paper on Credit financing in economic order policies for defective items with order overlapping in International conference on reliability, infocom, technologies and optimization in January 2013 at Amity University Noida, Uttar Pradesh.

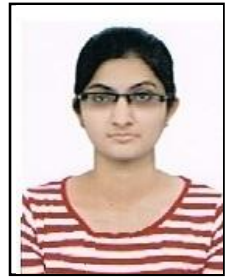

Ruchi Sharma has completed her bachelor degree in computer science \& engineering from Amity School of Engineering and Technology, New Delhi in July 2013 from IP University, Delhi. She has presented a paper on Credit financing in economic order policies for defective items with order overlapping in International conference on reliability, infocom, technologies and optimization in January 2013 at Amity University Noida, Uttar Pradesh. 